\title{
A Cartografia do Relevo: Uma Análise Comparativa de Técnicas para a Gestão Ambiental
}

\author{
Cenira Maria Lupinacci Cunha; Iandara Alves Mendes e Miguel Cezar Sanchez \\ Laboratório de Geomorfologia, Departamento de Planejamento Territorial e Geoprocessamento, \\ UNESP, Rio Claro. \\ Telefone: (019) 3523-6360 e-mail: luisgeo@uol.com.br.
}

\begin{abstract}
Resumo
No contexto da gestão ambiental, as formas de relevo e os processos geomorfológicos têm grande importância, tanto pelo fato de constituírem o substrato físico sobre o qual se desenvolvem as atividades humanas, como por responderem, muitas vezes de forma agressiva, às alterações provocadas por tais atividades. Desse modo, a representação cartográfica do relevo torna-se instrumental imprescindível para uma gestão ambiental adequada. Verifica-se, contudo, que as cartas normalmente elaboradas constituem-se em documentos complexos que, muitas vezes, dificultam a transmissão das informações aos leitores nãoespecializados. Neste contexto, o objetivo principal desta pesquisa foi testar, correlacionar e avaliar diversas propostas de representação cartográfica do relevo, analisando as limitações e possibilidades dos dados e informações fornecidos por tais produtos. Assim, para uma eficiente representação do relevo considera-se que em certas situações deve-se priorizar os elementos mais importantes de acordo com o objetivo da pesquisa.
\end{abstract}

Palavras Chave: cartografia, relevo, processos geomorfológicos.

\begin{abstract}
In the context of environmental management, the landforms and geomorphological process, have great importance, as much by the fact that they constitute the physical substrate where the human activities are developed as by, many times answering aggressively to the changes done by these activities. Thus, the relief cartographic representation becomes an indispensable instrument for an appropriate environmental management. However, we verify that maps often elaborated constitute themselves in complex documents that make difficult the transference of information to the not experts readers. In this context the main objective of this research was to test, to correlate and to evaluate several propositions of relief's cartography representation, analyzing limitations and possibilities of data and informations supplied by this products. So, for an efficient representation of relief, it is considered that in some situations it is necessary to give priority the most important elements according to the research objective.
\end{abstract}

Key words: cartographic, relief, geomorphological process.

\section{Introdução}

A geomorfologia, entendida como o estu-do das formas de relevo e dos processos responsáveis por sua elaboração, tem na cartografia geomorfológica um dos mais importantes veículos de comunicação e análise dos resultados obtidos. Extensas análises descritivas das formas, idade e gênese do relevo tornam-se muito mais ricas e lógicas quando acompanhadas por documentos cartográficos nos quais estas estejam espacializadas. Desse modo, Demek (1967) afirma que o mapeamento geomorfológico tem se tornado o principal método para o estudo e a pesquisa gemorfológica. Neste sentido, Balatka \& Sladek (1967) consideram que o mapeamento geomorfológico tanto resolve uma série de problemas geomorfológicos práticos como evita a ocorrência destes, principalmente através da indicação de áreas favoráveis ou desfavoráveis ao desenvolvimento das atividades humanas. 
Entretanto, a cartografia geomorfológica constitui-se em um tipo de mapeamento cuja complexidade é inerente ao próprio objeto de representação. O relevo apresenta uma diversidade de formas e de gênese, as quais são geradas por complicados mecanismos que atuam no presente e que atuaram no passado. Assim, segundo Ross (1991, pg. 17) “...interpretar o relevo não é simplesmente saber identificar padrões de formas ou tipos de vertentes e vales, não é simplesmente saber descrever o comportamento geométrico das formas, mas saber identificá-las e correlacioná-las com os processos atuais e pretéritos, responsáveis por tais modelados, e com isso estabelecer não só a gênese mas também sua cronologia, ainda que relativa". Desse modo, uma cartografia geomorfológica eficiente deve indicar todos estes elementos levantados como essenciais para o entendimento do relevo.

Contudo, representar todas estas informações em um único documento constitui-se em uma tarefa difícil de ser executada, levando à diversidade de procedimentos técnicos, os quais variam de acordo com as características da área pesquisada, a escala de trabalho e o objetivo do pesquisador. Desse modo, Argento (1995, pg. 366) afirma que "no contexto operacional, os mapeamentos geomorfológicos não seguem um padrão pré-definido, tanto em nível de escalas adotadas, como quanto à adoção de bases taxônomicas a elas aferidas".

De acordo com Fairbridge (1968), um mapa geomorfológico, para ser considerado completo, deve fornecer informações sobre a forma (morfologia), as dimensões (morfometria), a origem (morfogênese) e a idade (morfocronologia) de cada forma de relevo. A concepção deste autor (op. cit.) é compartilhada por autores brasileiros como Ross (1991), entre outros, embora existam muitas dificuldades no que se refere à legibilidade de documentos cartográficos que trazem este tipo de configuração. Assim, Ross (1991, pg. 55) afirma que "...fica claro que os geomorfólogos em geral são unânimes quanto à questão do conteúdo geral dos mapas...os mapas devem informar sobre os tipos de formas de relevo, gênese e idade. No entanto, o que parece mais problemático é a questão relativa à padronização ou uniformização da representação cartográfica, pois ao contrário de outros tipos de mapas temáticos, não se conseguiu chegar a um modelo de representação que satisfaça os diferentes interesses dos estudos geomorfológicos".

Nesse contexto, o objetivo deste artigo consiste em comparar duas propostas metodológicas diferenciadas para a elaboração de cartas geomorfológicas. Tais propostas utilizadas consistem em base para muitas adaptações feitas por pesquisadores brasileiros para os mapeamentos geomorfológicos realizados no país. Assim, foram realizados mapeamentos geomorfológicos com base na proposta do Centro de Geografia Aplicada de Strasbourg. (França, Tricart, 1965) e na proposta do International Institute for Aerial Survey and Earth Sciences (ITC, Holanda, Verstappen \& Zuidam, 1975).

A escolha destas propostas justifica-se por suas concepções diferenciadas. Desse modo, Tricart (1965) enfatiza a importância de se mapear as formações superficiais, interpretando tanto o grau de resistência destas, como da litologia que as sustentam. Já na proposta de Verstappen \& Zuidam (1975) verifica-se maior ênfase a simbologia linear que visa identificar as formas, sendo que, as características litológicas são identificadas somente pelo tipo de rocha predominante.

Como área de estudo foi selecionada a alta bacia do Rio Passa Cinco (SP), a qual se constituiu em área teste para os diversos mapeamentos realizados. A escolha deste setor da bacia hidrográfica deve-se ao fato da existência de grande variedade de feições geomorfológicas, as quais foram imprescindíveis para a realização desta pesquisa. Assim, foram mapeadas as formas de relevo, na escala de 1:50.000, relativas à área escolhida, envolvendo relevos vinculados à Depressão Periférica Paulista e à Província das Cuestas Arenítico-Basálticas do Estado de São Paulo. Dessa forma, as comparações em termos de legendas e procedimentos são válidas para este contexto litoestrutural, ou seja, para áreas que apresentam feições geomorfológicas esculpidas em bacias sedimentares.

\section{Procedimentos Técnicos}

A carta geomorfológica elaborada segundo a proposta de Tricart (1965) teve como fonte de dados pares estereoscópicos de fotografias aéreas, mapeamentos geológicos e a base cartográfica. O objetivo da realização deste mapeamento foi analisar a viabilidade e adaptação de tal proposta para as condições brasileiras, assim como as vantagens e desvantagens dos sistemas de legendas propostos pelo autor (op. cit.).

As cartas geomorfológicas detalhadas, na concepção de Tricart (1975), devem fornecer uma análise de todos os elementos do relevo, constituindose em um documento complexo que gera difíceis problemas cartográficos a serem resolvidos, os quais devem-se, em grande parte, à necessidade de sobreposição de símbolos e cores.

Para Tricart (1965), no universo das cartas geomorfológicas de detalhe é possível distinguir aquelas de escala 1:50.000 para menores como cartas de pequena escala, enquanto que as maiores constituem-se em cartas de grande escala. Contudo, o autor (op. cit.) chama a atenção para o fato de que cartas a 1:50.000 constituem-se na verdade na transição entre as duas concepções, havendo fatos normalmente mapeados em grandes escalas que podem ser representados nesta.

Tricart (1965) considera necessário que as cartas geomorfológicas detalhadas contenham quatro tipos de informação:

1. Morfometria - que pode ser representada, segundo o autor (op. cit.), por um fundo topográfico que contenha as drenagens e curvas de nível. Podem ainda ser acrescentados outros dados como declividade das vertentes, hierarquia da rede de drenagem, altura das bordas de terraços, de cornijas ou rebordos erosivos, desde que estes dados não prejudiquem a legibilidade da carta. No caso do mapeamento elaborado, verificou-se que acrescentar estes dados poderia transformar o documento cartográfico em um grande emaranhado de símbolos e 
números que comprometeriam sua leitura. Assim, manteve-se somente a primeira sugestão de Tricart (1965), representando os dados geomorfológicos mapeados sobre a base cartográfica digital.

2. Morfografia - identificada através dos diversos símbolos que localizam e espacializam as formas de relevo, representando a extensão destas. Estes símbolos devem já transmitir a noção dos processos que deram origem a tais formas. No mapeamento da alta bacia do rio Passa Cinco, procurou-se utilizar com fidelidade os símbolos propostos pelo autor (op. cit.), sendo as feições obtidas através da interpretação de pares estereoscópicos de fotografias aéreas (escala de 1:40.000) e editadas no programa Corel Draw 8.0.

3. Morfogênese - os símbolos que representam as formas devem trazer embutidos sua origem e gênese, a fim de tornar distinguíveis os processos morfogenéticos atuantes na área. No caso da legenda proposta por Tricart (1965), adotada no mapeamento da alta bacia do rio Passa Cinco, teve-se a preocupação de se realizar este procedimento através do agrupamento dos símbolos em grandes grupos de modelados, conforme a proposta do autor (op. cit.).

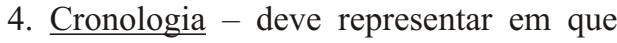
momento da história morfogenética da região as formas ou o conjunto destas se desenvolveram. Tal representação pode ser elaborada através do uso de cores. Este tipo de informação, segundo Tricart (1965), constitui-se no de mais difícil obtenção, assim como no mais complexo e de difícil precisão na cartografia geomorfológica. Com vistas a este problema, optou-se então por não datar os fenômenos mapeados na alta bacia do rio Passa Cinco, principalmente devido ao fato destes serem gerados principalmente pela atuação dos escoamentos pluvial e fluvial, muito ativos atualmente na região. Desse modo, os símbolos utilizados são na coloração negra, proposta pelo autor (op. cit.) para os fenômenos atuais.

Além destes dados, Tricart (1965) recomenda como essencial a representação, nas cartas geomorfológicas, dos dados referentes ao arcabouço estrutural, os quais foram mapeados em dois níveis:

a) Feições estruturais - representadas através de símbolos, como as falhas e o front cuestiforme;

b) Dados litológicos - representados por tramas coloridas, sendo as litologias mais resistentes indicadas por cores compactas e as menos resistentes por tramas coloridas cada vez mais espaçadas de acordo com o grau de incoerência do material. A avaliação do grau de resistência da litologia da alta bacia do rio Passa Cinco foi feita tanto através da análise da bibliografia, como através da análise das formas de relevo observadas em cada unidade litológica. Para as litologias sedimentares, caso predominante na alta bacia do rio Passa Cinco, o autor (op. cit.) propõe que se utilize a cor cinza. A Formação Serra Geral constitui-se em exceção, já que engloba basaltos e arenitos silicificados. Devido a esta mistura entre litologias ígneas e sedimentares, optou-se, na representação da alta bacia, por utilizar a cor referente à litologia sedimentar que constitui-se naquela predominante nas demais formações.

Com o objetivo de estabelecer parâmetros de comparação a mesma área foi mapeada ainda de acordo com a orientação proposta pelo International Institute for Aerial Survey and Earth Sciencies (ITC, Holanda), publicada por Verstappen \& Zuidam, em 1975.

Segundo os autores (op. cit.), os mapas geomorfológicos podem ser de três tipos, a saber:

1. "Mapas preliminares: elaborados antes do trabalho de campo, com base somente na interpretação de pares estereoscópicos de fotografias aéreas";

2. "Mapas com fins gerais: são resultado de investigações geomorfológicas puras, sem fins específicos";

3. "Mapas com fins especiais: podem ser de morfoconservação ou hidromorfológicos e visam a orientar ou resolver problemas específicos".

Diante deste contexto, optou-se neste trabalho por realizar um mapa com fins gerais, visto que o objetivo principal era avaliar a metodologia proposta pelos autores (op. cit.). Para tanto, foram realizadas as seguintes etapas:

1. Elaboração da carta base: Verstappen \& Zuidam (1975) compreendem por carta base a integração dos dados topográficos com os litológicos da área a ser mapeada. Tais dados devem ser representados em tons de cinza, contudo, quando a litologia for fator primordial na definição dos fatos geomorfológicos observados, esta pode ser representada em tons mais escuros. No caso da alta bacia do rio Passa Cinco optou-se por representá-la em tons claros, assim como a topografia, devido ao grande número de feições a serem sobrepostas à carta base. Além disso, foi seguida a orientação dos autores (op. cit.), que consiste em classificar os dados litológicos de acordo com os tipos de rocha predominante dentro de cada formação, os quais são representados por símbolos.

2. Realização da foto interpretação: para a realização da fotointerpretação foram utilizados pares estereoscópicos de fotografias aéreas na escala de 1:40.000, cujos dados obtidos foram compatibilizados posteriormente através do uso do aerosketmaster. Para o mapeamento das feições identificadas utilizou-se a simbologia proposta por Verstappen \& Zuidam (1975), na qual os símbolos são coloridos de acordo com sua origem. Assim, as formas de origem estrutural foram mapeadas com símbolos de cor vermelha, as de origem denudativo de marrom, as de origem fluvial de azul escuro e as morfométricas e topográficas de cor preta a cinza. Convém esclarecer que para as curvas de nível atribuiu-se um tom um pouco mais claro (acinzentado), seguindo-se a recomendação dos autores (op. cit.) para a carta base, visto que dessa forma a legibilidade do produto final apresentou melhor resultado. Outro fato importante que merece esclarecimento é que, apesar de terem sido seguidos os procedimentos para a elaboração de uma carta com fins gerais, verificou-se que os símbolos da proposta adotada muitas vezes eram comuns para este tipo de carta e aquelas de morfoconservação. Assim, os símbolos que identificam os terraços agrícolas, os tipos de linhas de cumeada e de formas de vertente são recomendados para os dois tipos de carta.

3. Realização dos trabalhos de campo e 
edição da carta - Após a fotointerpretação e montagem de uma carta preliminar, foram realizados os trabalhos de campo com o objetivo de reambular os dados mapeados. O trabalho final de edição da carta consistiu em reunir em um único documento cartográfico tanto a base, com os dados litológicos e as curvas de nível, como os dados obtidos por foto interpretação. Assim como na outra carta geomorfológica, tais símbolos utilizados na fotointerpretação foram editados através do programa Corel Draw 8.

\section{Análise Comparativa das Propostas}

Os documentos cartográficos elaborados apresentam grande complexidade para a publicação devido à intensa utilização de cores. Dessa forma, serão aqui apresentadas as legendas (Fig. 1), em branco e preto, as quais encontram-se separadas dos mapas (Fig. 2 e 3) a fim de possibilitar melhor visualização das propostas utilizadas.

Convém esclarecer ainda que os mapas, aqui apresentados em preto e branco, foram elaborados originalmente em cores na escala de 1:50.000.

Inicialmente, construiu-se um quadro (Quadro 1) o qual busca sintetizar a comparação feita entre as propostas, sendo que cada um dos elementos diferenciados será comentado a seguir.

\begin{tabular}{|c|l|l|}
\hline \multicolumn{3}{|c|}{ Quadro 1 Comparação entre as propostas de Tricart (1965) e Verstappen \& Zuidam (1975) } \\
\hline $\begin{array}{c}\text { Elemento } \\
\begin{array}{c}\text { Litologia e formações } \\
\text { superficiais }\end{array}\end{array}$ & \multicolumn{1}{|c|}{ Tricart (1965) } & \multicolumn{1}{c|}{ Verstappen \& Zuidam (1975) } \\
\hline Formas de vertentes & $\begin{array}{l}\text { Não apresenta simbologia para a } \\
\text { identificação das formas, somente para } \\
\text { identificar os tipos de escomento. }\end{array}$ & $\begin{array}{l}\text { Apresenta simbologia para identificar } \\
\text { formas etipos de escoamento. }\end{array}$ \\
\hline Rupturas topográficas & $\begin{array}{l}\text { Apresenta simbologia que identifica } \\
\text { diversos graus de desníveis. }\end{array}$ & $\begin{array}{l}\text { Apresenta simbologia única, não possi- } \\
\text { bilitando identificar os desníveis. }\end{array}$ \\
\hline Colos & $\begin{array}{l}\text { Apresenta simbologia específica para } \\
\text { identificar a presença de colos } \\
\text { topográficos. }\end{array}$ & $\begin{array}{l}\text { Não contempla tal feição topográfica } \\
\text { com simbologia específica } \\
\text { A }\end{array}$ \\
\hline $\begin{array}{c}\text { Rupturas topográficas } \\
\text { em cursos fluviais. }\end{array}$ & $\begin{array}{l}\text { Apresenta simbologia que permite } \\
\text { identificar a magnitude de tais } \\
\text { rupturas. }\end{array}$ & $\begin{array}{l}\text { presenta simbologia única para rupturas } \\
\text { de diversas magnitudes. }\end{array}$ \\
\hline $\begin{array}{c}\text { Agrupamento das } \\
\text { feições morfográficas. }\end{array}$ & $\begin{array}{l}\text { Apresenta grupo específico para o } \\
\text { modelado antrópico. }\end{array}$ & $\begin{array}{l}\text { Não contempla as feições antrópicas em } \\
\text { grupo específico. }\end{array}$ \\
\hline Morfometria & $\begin{array}{l}\text { Contempla curvas de nível e linha de de } \\
\text { cumeada como aspectos morfomé- } \\
\text { tricos. }\end{array}$ & $\begin{array}{l}\text { Apresenta tanto curvas de nível e linhas } \\
\text { de cumeada, como outras feições morfo- } \\
\text { lógicas no grupo de morfometria. }\end{array}$ \\
\hline Uso de cores & $\begin{array}{l}\text { Sugere o uso de cores para a cronologia e } \\
\text { grau de resistência da litologia. }\end{array}$ & $\begin{array}{l}\text { Usa cores diferenciadas para cada grupo } \\
\text { de elementos. }\end{array}$ \\
\hline
\end{tabular}


Fig. 1 - Sistemas de Legenda das Cartas Geomorfológicas

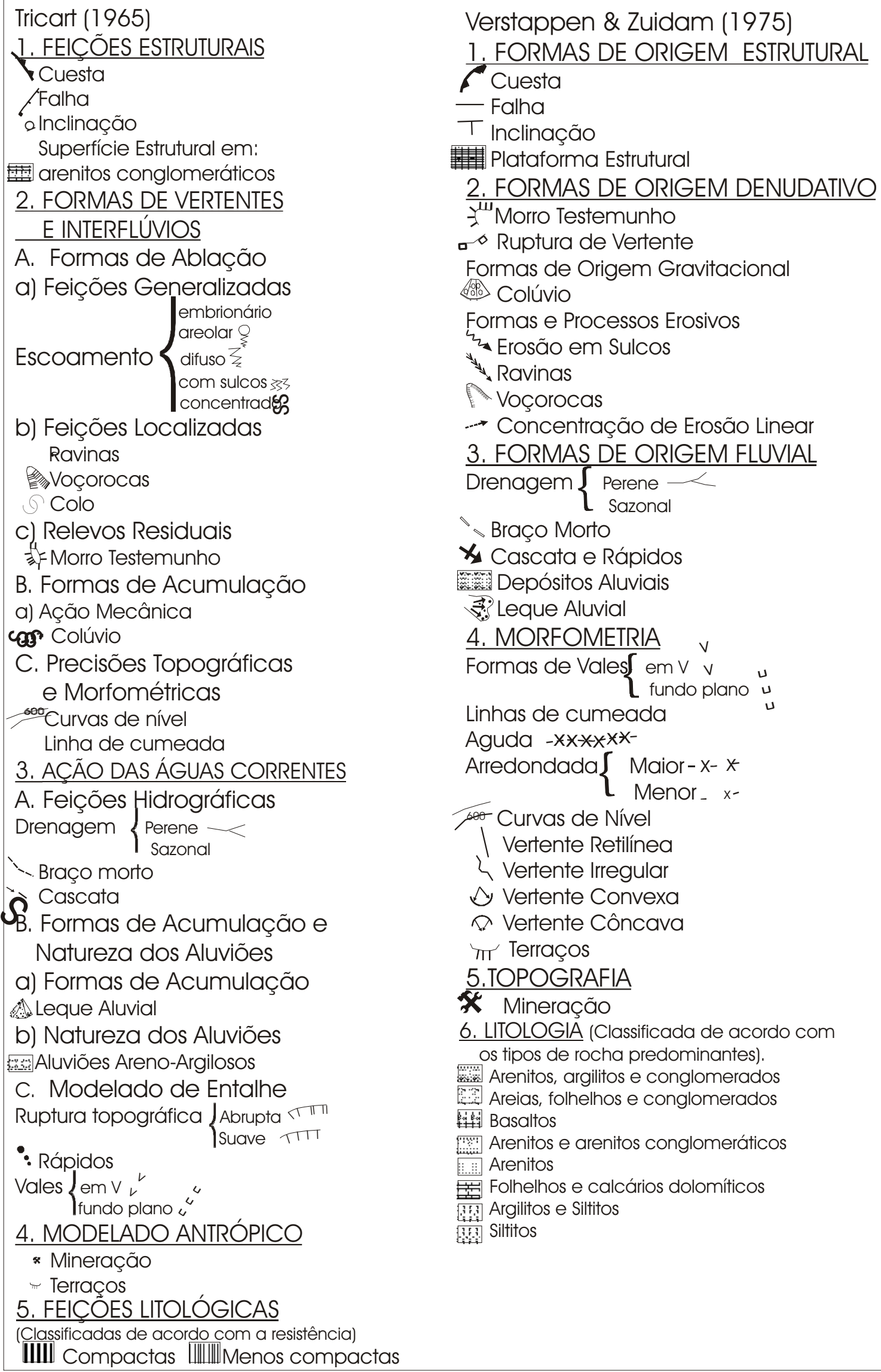

Verstappen \& Zuidam (1975)

1. FORMAS DE ORIGEM ESTRUTURAL

Cuesta

- Falha

T Inclinação

Plataforma Estrutural

2. FORMAS DE ORIGEM DENUDATIVO

:"'Morro Testemunho

$\because \therefore$ Ruptura de Vertente

Formas de Origem Gravitacional

啲 Colúvio

Formas e Processos Erosivos

Erosão em Sulcos

Ravinas

Voçorocas

- Concentração de Erosão Linear

3. FORMAS DE ORIGEM FLUVIAL Drenagem $\left\{\begin{array}{l}\text { Perene } \\ \text { sazonal }\end{array}\right.$

Braço Morto

\ Cascata e Rápidos

Depósitos Aluviais

3.ं. Leque Aluvial

4. MORFOMETRIA

Formas de Vales $\left\{\begin{array}{l}\text { em } v \\ \text { fundo plano } \\ u\end{array}\right.$

Linhas de cumeada

Aguda $-x \times x \cdot x \times x-$

Arredondada $\left\{\begin{array}{l}\text { Maior }-x-x \\ \text { Menor - } x \text { - }\end{array}\right.$

Curvas de Nível

Vertente Retilínea

4 Vertente Irregular

$\diamond$ Vertente Convexa

ه Vertente Côncava

in Terraços

5.TOPOGRAFIA

* Mineração

6. LITOLOGIA (Classificada de acordo com os tipos de rocha predominantes).

Arenitos, argilitos e conglomerados

Areias, folhelhos e conglomerados

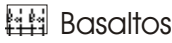

Arenitos e arenitos conglomeráticos

Arenitos

Folhelhos e calcários dolomíticos

Argilitos e Siltitos

Siltitos 

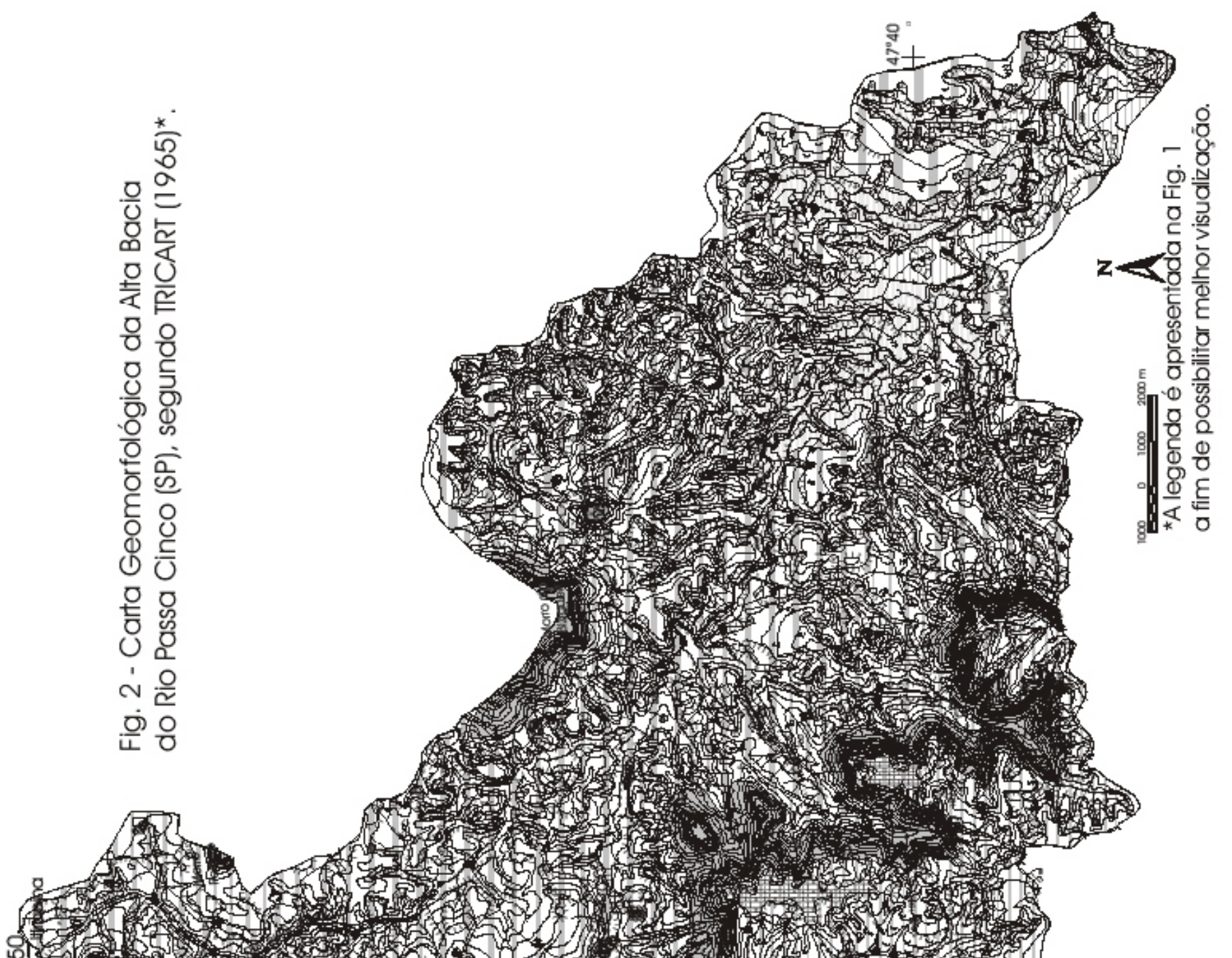

나의

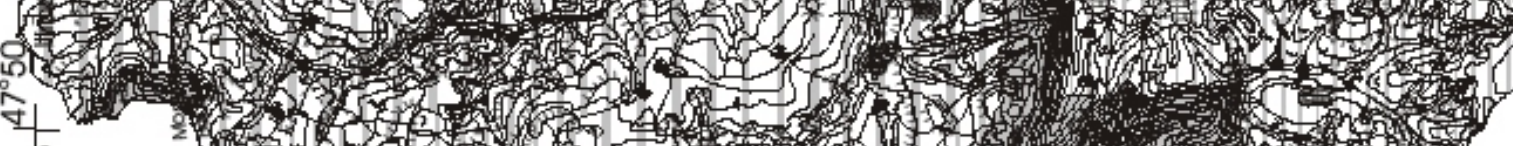

สิ
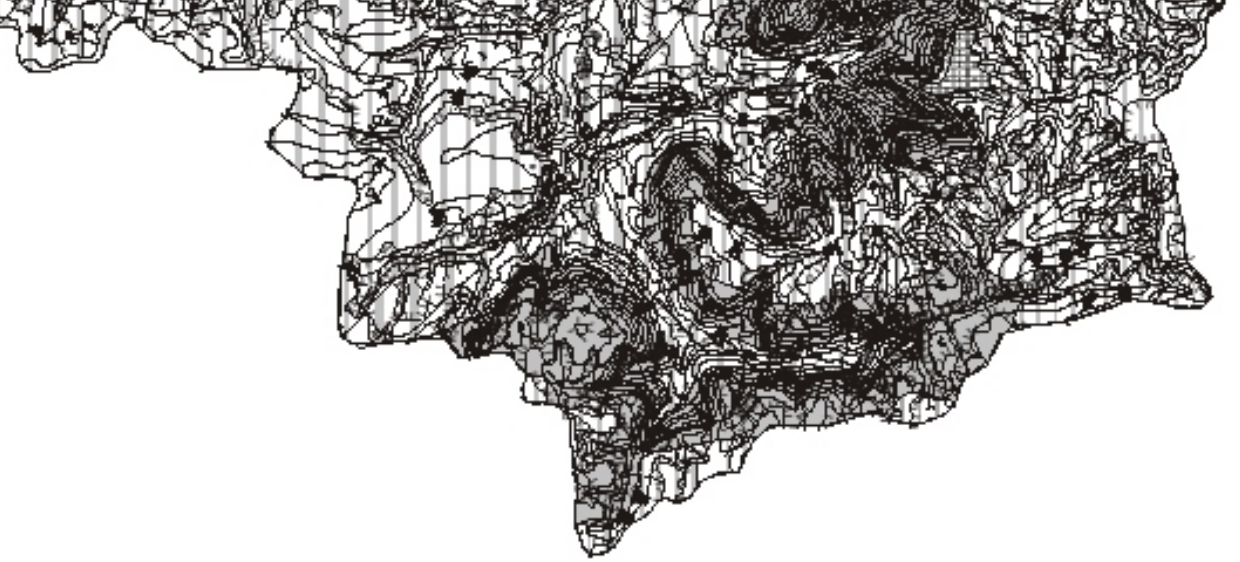

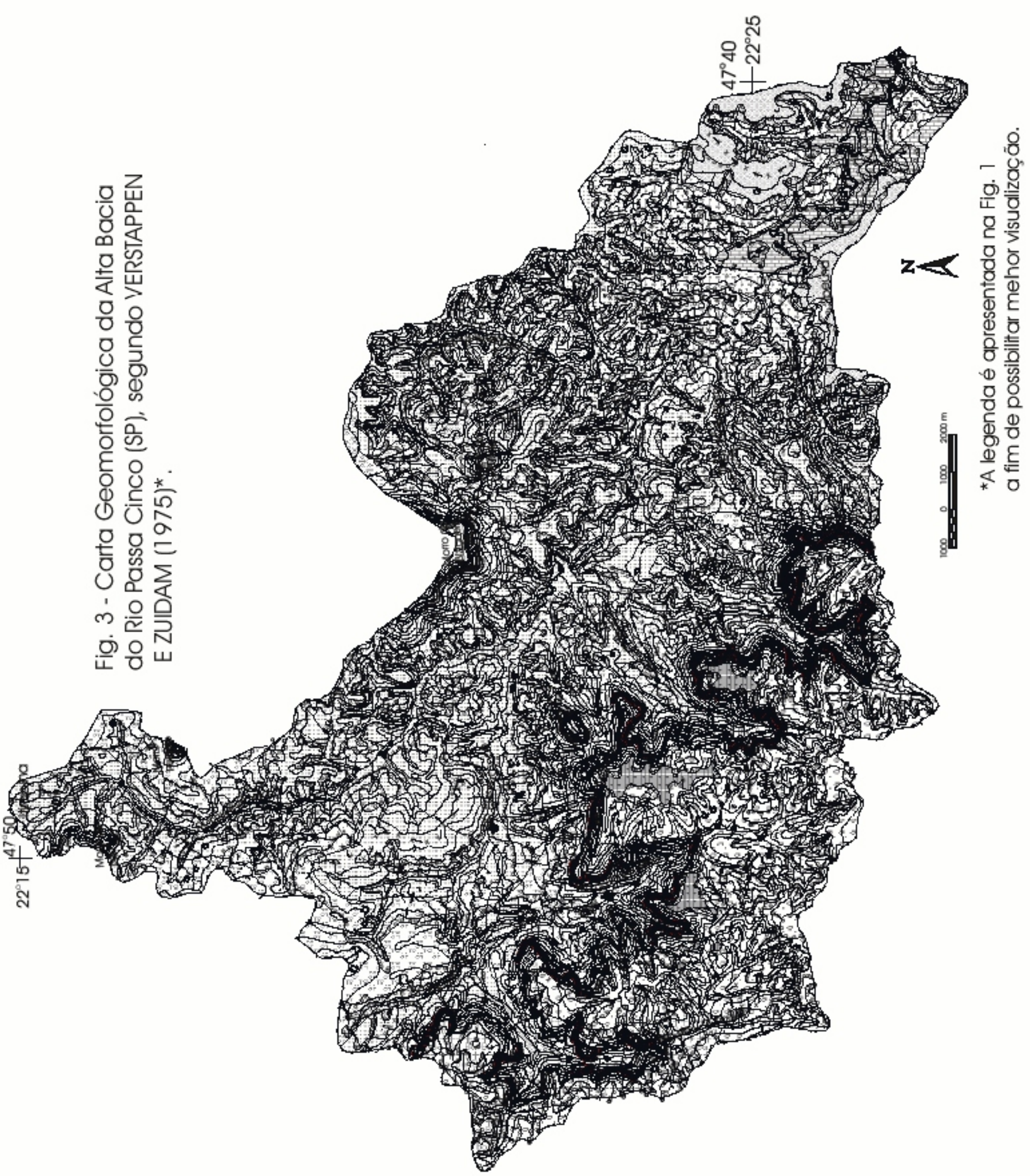

प 
Verifica-se, através da análise dos documentos cartográficos elaborados, que a orientação de Tricart (1965) apresenta uma ênfase maior para as formações superficiais. Assim, sejam superfícies estruturais ou depósitos aluviais, a recomendação do autor (op. cit.) é que se identifique a natureza granulométrica do material de superfície. Desse modo, se o trabalho contempla áreas de pequena extensão, é possível obter informações sobre tais características granulométricas. Contudo, em áreas de grande extensão é difícil realizar trabalhos de campo e análises granulométricas que contemplem, por exemplo, todas as planícies fluviais encontradas. No caso da alta bacia do rio Passa Cinco, como na maioria das planícies aluviais, de pequena extensão, estas só foram passíveis de mapeamento em poucos pontos nos quais se verificou em campo sua constituição granulométrica. Nas demais situações, procurou-se transmitir a idéia da existência de pequenas planícies através do registro de vales de fundo plano.

Segundo Tricart (1975), a cartografia geomorfológica não deve somente indicar as formas de relevo, mas sim interpretá-las com base em sua constituição litológica e nos processos atuantes sobre tais litologias. Tal interpretação já deve ser feita com relação às próprias formações geológicas. $\mathrm{O}$ autor (op. cit.) enfatiza que os dados geológicos de uma carta geomorfológica não devem ser só transcrição do mapa geológico, devem representar a interpretação do geomorfólogo das condições de resistência da litologia à atuação dos processos geomórficos. Assim, as formações são representadas por tramas que quando mais esparsas indicam menor grau de resistência. Contudo, a legibilidade e identificação deste grau de resistência fica bastante comprometida no produto final, no qual, a estes dados, sobrepõem-se as curvas de nível (a fim de indicar a morfometria da área) e os símbolos que identificam a morfografia e os processos geomórficos atuantes.

Com relação à simbologia, é extremamente difícil realizar um mapeamento geomorfológico sem a existência de símbolos que indiquem a forma da vertente. Para Tricart (1975), a forma deve estar implícita quando se indicam os tipos de escoamento, ou seja, os processos pluvio-erosivos atuantes. Contudo, o escoamento superficial mantém relação estreita não somente com a forma, mas também com o uso da terra que sobre esta forma se estabelece e com o tipo de solo. Assim, áreas ocupadas por densa cobertura florestal tendem a apresentar formas de escoamento diferenciadas daquelas menos protegidas, mesmo que a forma da vertente seja semelhante. Por outro lado, vertentes com solos mais arenosos tendem a permitir maior infiltração de água do que aquelas constituídas por material superficial mais argiloso sob as mesmas condições de forma, uso, comprimento e declive. Outro fato que deve ser considerado é que se o mapeamento geomorfológico for também utilizado por outros profissionais, estes terão mais facilidade em analisar o significado da forma do que do processo. Neste contexto, a indicação dos tipos de escoamento, feita na carta da alta bacia do rio Passa Cinco, refere-se principalmente àqueles que devem predominar de acordo com a forma identificada e com as marcas de tal escoamento verificadas em campo.

Outro tipo de símbolo que não consta na proposta de Tricart (1965) e que é de grande importância para a caracterização morfogenética da área é o tipo de contato vertente-fundo de vale. A identificação de contatos vertente-fundo de vale em formas suaves ou em ângulos retos pode auxiliar na identificação dos processos mais ativos na área. No caso da alta bacia do rio Passa Cinco, devido à escala utilizada, dificilmente seria possível indicar este tipo de contato. Porém, em trabalhos mais detalhados, em que estas feições sejam passíveis de mapeamento, este tipo de informação pode ser bastante útil na gestão ambiental, principalmente em se tratando de avaliação de processos erosivos, nos quais os contatos suaves podem indicar a ocorrência de material vindo da vertente que, atualmente, deposita-se neste setor do relevo.

Na proposta de legenda de Verstappen \& Zuidam (1975), constata-se que as formas de contato de vertente-fundo de vale também não são contempladas com simbologia. Nesta proposta, contudo, além dos tipos de escoamento, figuram também simbologia para as formas de vertente. Desse modo, quando houver certeza sobre o tipo de escoamento, é possível utilizar os símbolos propostos para este ou, então, utilizar símbolos específicos para cada forma de vertente. Neste aspecto, tal proposta é mais versátil do que aquela elaborada por Tricart (1965).

Com relação à litologia também existem diferenciações. Verstappen \& Zuidam (1975) sugerem que se indique os dados litológicos através de tramas que informam sobre o tipo de material predominante dentro de cada formação geológica. É nítido que interpretar o grau de resistência destas formações, como o proposto por Tricart (1965), gera um tipo de informação bem mais relevante para o mapeamento geomorfológico. Contudo, nas duas propostas, a grande sobreposição de símbolos e curvas de nível que é exigida para a configuração do produto final gera dificuldade na legibilidade dos dados litológicos.

Com relação ainda à simbologia linear, verifica-se que o símbolo de ruptura topográfica proposto por Verstappen \& Zuidam (1975) não permite a distinção entre aquelas mais suaves e mais abruptas, enquanto que na proposta de Tricart (1965) é possível identificar vários desníveis de rupturas. Dessa forma, quando se trabalha com escalas de pequeno detalhe é difícil discernir tais diferenciações, em função da grande eqüidistância entre as curvas de nível não permitir uma segura quantificação de tais desníveis. Contudo, para estudos de maior detalhe, o autor (op. cit.) apresenta um maior número de opções do que Verstappen \& Zuidam (1975).

Na proposta de Verstappen \& Zuidam (1975) verifica-se ainda que não há símbolo próprio para a indicação de colos topográficos, elemento importante quando se trata de analisar a evolução do modelado. Outro fato parcialmente contemplado por tal proposta é a ruptura topográfica em cursos fluviais, a qual apresenta um único símbolo para cascatas e rápidos. Considera-se importante distinguir, mesmo que de forma geral, as dimensões destas rupturas, já que, caso 
contrário, como na área estudada, os símbolos que marcam as verdadeiras cascatas que se formam no front cuestiforme serão os mesmos que marcam pequenas rupturas ao longo dos cursos fluviais.

Comparando as duas propostas, chama atenção a forma pela qual os símbolos são agrupados. Na proposta de Tricart (1965), apesar da ênfase dada à interpretação das formas e dos processos responsáveis por sua esculturação, verifica-se que muitos símbolos são agrupados por tipos de formas, sendo os grandes grupos estruturados em feições estruturais, formas de vertentes e interflúvios, ação das águas correntes e modelado antrópico. Assim, por exemplo, no grupo referente às formas de vertentes não constam símbolos para estas, mas sim para os tipos de escoamento.

Já na proposta de Verstappen \& Zuidam (1975) verifica-se que as formas são agrupadas de acordo com sua origem, formando grandes grupos denominados como de origem estrutural, denudativo e fluvial. Os autores (op. cit.) agrupam separadamente ainda a morfometria e a topografia, enquanto para Tricart (1965) tais feições constituem-se em subgrupo dentro daquele de formas de vertente e interflúvios. Convém notar que Verstappen \& Zuidam (1975) incluem na morfometria símbolos para formas de vale, vertentes, linhas de cumeada, terraceamentos agrícolas, além das curvas de nível. Assim, ao se considerar que na maior parte da bibliografia há consenso de que a morfometria constitui-se nas medidas (quantificação) das formas, constata-se que, com exceção das curvas de nível, os demais elementos não atendem a tal definição e, portanto seria adequado estarem em outro tipo de grupo. Outro grupo não contemplado pelos autores (op. cit.) é o modelado antrópico. Assim, no mapeamento da alta bacia do rio Passa Cinco, baseado nesta proposta, os símbolos para terraços agrícolas estão registrados no grupo da morfometria e para áreas de mineração no grupo da topografia. Neste aspecto a proposta de Tricart (1965) é mais interessante, já que é possível separar tais elementos em um grupo denominado modelado antrópico. Além disso, deve-se considerar que atualmente a interferência antrópica nas feições geomorfológicas é cada vez maior e, quando se trata de gestão ambiental, o mapeamento de tais interferências é imprescindível.

Ainda na proposta de Verstappen \& Zuidam (1975), cada grupo de símbolos é marcado por uma cor: os fenômenos estruturais são marcados por símbolos vermelhos, os denudativos na cor marrom, a morfometria em preto e os fluviais na cor azul. Estas cores causam problemas de legibilidade quando os símbolos são sobrepostos sobre as curvas de nível e a litologia, tornando difícil a distinção imediata destes, principalmente dos denudativos em uma área como a aqui estudada, na qual tais feições são em grande número e próximas umas das outras. Além disso, o símbolo sugerido para ruptura topográfica, que se constitui de traços com pequenas figuras associadas, dificulta ainda mais a leitura.

Estes fatos servem para ilustrar a complexidade dos elementos mapeados em cartas geomorfológicas. Assim, por exemplo, as rampas coluviais são indicadas por Tricart (1965) como formas de acumulação, dentro do grupo de formas de vertente e interflúvios. Já Verstappen \& Zuidam (1975) incluem estas no subgrupo formas de origem gravitacional, que pertence ao grupo formas de origem denudativa. Sabe-se que tais feições são formas de acumulação normalmente posicionadas nas vertentes, geradas por processos gravitacionais. Desse modo, as duas concepções estão corretas, porém cada uma delas enfatiza um aspecto diferente da mesma feição geomorfológica.

\section{Considerações Finais.}

As duas propostas analisadas constituem-se em instrumental de trabalho importante para a cartografia geomorfológica voltada para a gestão ambiental. Cada uma delas apresenta aspectos que podem ser utilizados a depender das condições de trabalho, das características da área e da escala adotada. Desse modo, é impossível afirmar que uma das propostas é mais "correta" do que a outra; para cada situação, ou até mesmo dentro de uma mesma carta, existem aspectos vantajosos de ambas as propostas que podem ser utilizados, dependendo do objetivo da pesquisa e também da escala de mapeamento.

\section{Referências Bibliográficas}

Argento, M.S.F. (1995) Mapeamento geomorfológico. In: GUERRA, A. J. T.; CUNHA, S.B. da (org.) Geomorfologia: Uma atualização de bases e conceitos. Rio de Janeiro, Bertrand Brasil.

Balatka, B.; SLADEK, J. (1967) Problem of the conception of the detailed geomorphological map. In: DEMEK, J. (ed.) Progress made in geomorphological mapping. Brno: IGU Commission on Applied Geomorphology: p.179-192.

Demek, J. (1967) Generalization of geomorphological maps. In: DEMEK, J. (ed.) Progress made in geomorphological mapping. Brno, IGU Commission on Applied Geomorphology: p.36-72.

Fairbridge, R. W. (1968) The encyclopedia of geomorphology. New York, Reinhold Book Corporation.

Ross, J. L. S. (1991) Geomorfologia: Ambiente e planejamento. São Paulo, Contexto.

Tricart, J. (1965) Principes et méthodes de la géomorphologie. Paris, Masson.

Verstapen, H.T.; ZUIDAM, R.A. van (1975) ITC System of geomorphological survey. Netherlands, Manuel ITC Textbook, Vol. VII, Chapter VII.3 